\title{
Del relato testimonial al cuerpo de la memoria: investigación performativa sobre la escenificación de testimonios de niños chilenos en dictadura*
}

\author{
FROM TESTIMONIAL NARRATIVE TO THE BODY OF MEMORY: \\ PERFORMATIVE RESEARCH ABOUT THE PERFORMANCE OF TESTIMONIES \\ OF CHILEAN CHILDREN IN DICTATORSHIP
}

DOS TESTEMUNHOS AO CORPO DA MEMÓRIA: INVESTIGAÇÃO

PERFORMATIVA DA ENCENAÇÃO DE TESTEMUNHOS DE CRIANÇAS

CHILENAS NA DITADURA

\section{María José Contreras Lorenzini** \\ Cuadernos de Música, Artes Visuales y Artes Escénicas \\ / Volumen 12 - Número 1 / Enero - Junio de 2017 \\ / ISSN 1794-6670/ Bogotá, D.C., Colombia / pp. 173-196}

Fecha de recepción: 6 de mayo de 2016

Fecha de aceptación: 9 de junio de 2016

Disponible en línea: febrero 20 de 2017

doi:10.11144/Javeriana.mavae12-1.rtcm

* Artículo de investigación. Resultado del proyecto Fondecyt de iniciación n. ${ }^{\circ} 11090155$ El cuerpo en la memoria/la memoria del cuerpo. Investigadora responsable:

María José Contreras Lorenzini.

* Doctora en Semiótica por la Universidad de Bolonia. Psicóloga por la Universidad Católica de Chile. Directora teatral y artista de performance. Jefa del Programa de Doctorado en Artes (especialidad artes visuales, música y artes escénicas) y docente de la Escuela de Teatro de la Pontificia Universidad Católica de Chile. Correo electrónico: mcontrel@uc.cl 


\section{Resumen}

En el presente artículo presento una exégesis de la investigación performativa Teatro y memoria: estrategias de re-presentación y elaboración escénica de la memoria traumática infantil, cuyo objetivo general fue explorar estrategias de escenificación de testimonios de personas que fueron niños y niñas durante la dictadura en Chile. El proyecto se realizó en dos etapas: durante 2008 se recolectaron los testimonios y se desarrolló un primer laboratorio teatral; en una segunda etapa, realizada entre 2011-2012, se creó la obra testimonial Pajarito nuevo la lleva, que fue presentada en diversos espacios teatrales y de memoria en Santiago de Chile. En este artículo, se identifican las distintas estrategias de puesta en escena y puesta en cuerpo de los testimonios recolectados y se da cuenta de algunas posibilidades de re-elaboración escénica de memorias del posconflicto.

Palabras claves: teatro; investigación performativa; testimonio; dictadura; Chile.

\section{Abstract}

In this article I present an exegesis of the performative research "Theatre and memory. Strategies of (re)presentation and performative elaboration of children's traumatic memory" whose general objective was to explore performance strategies to stage testimonies of people who were children during the dictatorship in Chile. The project was conducted in two phases: in 2008 the testimonies were collected and we developed a first theatrical laboratory, in a second stage, developed between 2011-2012, we created the testimonial play Pajarito Nuevo la lleva, presented in various theatres and memory sites in Santiago de Chile. In the present article I identify different strategies of mise-en-scene and embodiment of the collected testimonies, accounting of some possibilities of theatrical reelaboration of post-conflict memories.

Keywords: theatre; performance research; testimony; dictatorship; Chile.

\section{Resumo}

Neste artigo vou apresentar uma exegese da pesquisa performativa "Teatro e memória. Estratégias de representação e elaboração cênica da memória traumática infantil", cujo objetivo geral foi o de explorar estratégias de tradução performativa dos testemunhos coletados entre aqueles que eram crianças na época da ditadura no Chile. O projeto foi realizado em duas etapas: em 2008, os testemunhos foram coletados e um primeiro laboratório teatral desenvolvido, em uma segunda etapa realizada entre 2011-2012, se criou a obra do teatro Pajarito nuevo la lleva que foi apresentada em vários espaços teatrais e de memória em Santiago de Chile. Neste artigo eu vou identificar diferentes estratégias de encenação e corporização dos testemunhos recolhidos, apresentando algumas possibilidades cênicas de re-elaboração da memória do pós-conflito.

Palavras chave: teatro; pesquisa performativa; testemunho; ditatura; Chile. 


\section{INTRODUCCIÓN}

El compromiso de la comunidad teatral chilena con la reconstrucción de la memoria se enraíza en la dictadura misma, periodo en el cual muchos teatristas arriesgaron sus vidas para denunciar, protestar y evidenciar las violaciones a los derechos humanos perpetrados por el régimen cívico-militar. En los años de la transición a la democracia, el teatro siguió siendo una suerte de trinchera de lucha contra la amnesia instaurada por los gobiernos de la posdictadura, que, fieles a su "política del consenso", se adhirieron a un pacto de silencio que se perpetúa incluso hasta hoy'. En 2013, con motivo de la conmemoración de los cuarenta años del golpe de estado en Chile, la escena teatral del país se comprometió con aún más vigorosidad con temáticas de memoria: se repusieron obras emblemáticas de los primeros años de la posdictadura y se estrenaron nuevas obras que desde distintas ópticas y perspectivas trataban temáticas relacionadas con la dictadura o la denominada transición a la democracia.

La mayor parte de las veces el trabajo teatral sobre la memoria no ha tenido fines investigativos, sino que se ha entendido más bien como un ejercicio creativo. Por esto existe una escasa producción de registros y genéticas de la producción de obras teatrales que traten temáticas de memoria. En el presente artículo, expongo una experiencia, desarrollada entre 2008 y 2012, que conjugó el trabajo teatral y la reflexión teórica, bajo la forma de una investigación performativa —una indagación conducida por la práctica artística) que buscaba generar nuevas formas de conocer, aprehender y producir procesos de escenificación de la memoria en Chile.

En 2008, Milena Grass me invitó a participar en la investigación Teatro y memoria: estrategias de re-presentación y elaboración escénica de la memoria traumática infantil, que buscaba explorar distintas modalidades de trabajo escénico de la memoria de la posdictadura en Chile. Junto con Milena Grass y Nancy Nicholls, formulamos un diseño de investigación que partió de las siguientes preguntas: ¿de qué modo el teatro puede recuperar, reconstruir y resemantizar la memoria?, ¿cómo se inscriben en el cuerpo las huellas de los acontecimientos y cómo esas huellas pueden ser re-presentadas por actores en escena? La investigación se propuso como objetivo general explorar y sistematizar distintas modalidades de puesta en cuerpo y en escena de testimonios de personas que fueron niños durante la dictadura en Chile.

La investigación se desarrolló en dos etapas principales. La primera etapa del proyecto fue financiada por la Vicerrectoría de Investigación y los Laboratorios Teatrales de la Escuela de Teatro de la Pontificia Universidad Católica de Chile². Esta primera etapa fue dirigida por el equipo interdisciplinario antes mencionado: Milena Grass, Nancy Nicholls y quien escribe, María José Contreras. Las tres investigadoras diseñamos la metodología del proyecto en conjunto y pusimos la atención en los diálogos interdisciplinarios que podían emerger a partir de nuestros distintos campos de competencia: la práctica escénica, la actuación teatral, la dirección teatral, los estudios de memoria, la historia oral y los estudios del posconflicto.

La investigación teórica, dirigida por Milena Grass, incluyó una revisión y discusión bibliográfica sobre los principales estudios nacionales e internacionales que relacionaran teatro y memoria. Este barrido inicial nos corroboró la impresión inicial respecto de la inexistencia de investigaciones publicadas que dieran cuenta del proceso de escenificación de memorias del posconflicto en Chile, lo cual sin duda motivó en forma más decidida nuestro proyecto.

Nancy Nicholls lideró la recolección de testimonios y realizó entrevistas a trece personas que tenían entre 5 y 10 años en dos momentos cruciales de la dictadura en Chile: el golpe de Estado (1973) o las protestas de la década de $1980^{3}$. Nicholls seleccionó la muestra a 
partir de informantes clave y con la técnica de bola de nieve y contactó a personas que conocía personalmente y luego reclutó a personas sugeridas por otros entrevistados. En el proceso, la muestra se fue intencionando, realizando un muestreo guiado teóricamente que cumpliera con los siguientes criterios: personas que no fueran víctimas directas de violaciones a los derechos humanos, pertenecientes a distintos estratos socioeconómicos y de ambos géneros. De esta forma se intentaba obtener una muestra no exhaustiva pero suficientemente transversal. Las entrevistas fueron grabadas en video y luego transcritas.

La transcripción de las entrevistas, así como los videos, constituyeron el material fuente del trabajo del laboratorio teatral que dirigí. El laboratorio incluyó la participación de cuatro estudiantes de la Escuela de Teatro de la Universidad Católica y dos actrices profesionales ${ }^{4}$. Como detallaré más adelante, a partir de diversos ejercicios, exploramos formas de puesta en cuerpo y en el espacio del material testimonial. Producto del trabajo laboratorial surgió un work in progress, que fue presentado al público en octubre de 2008 (figura 1).

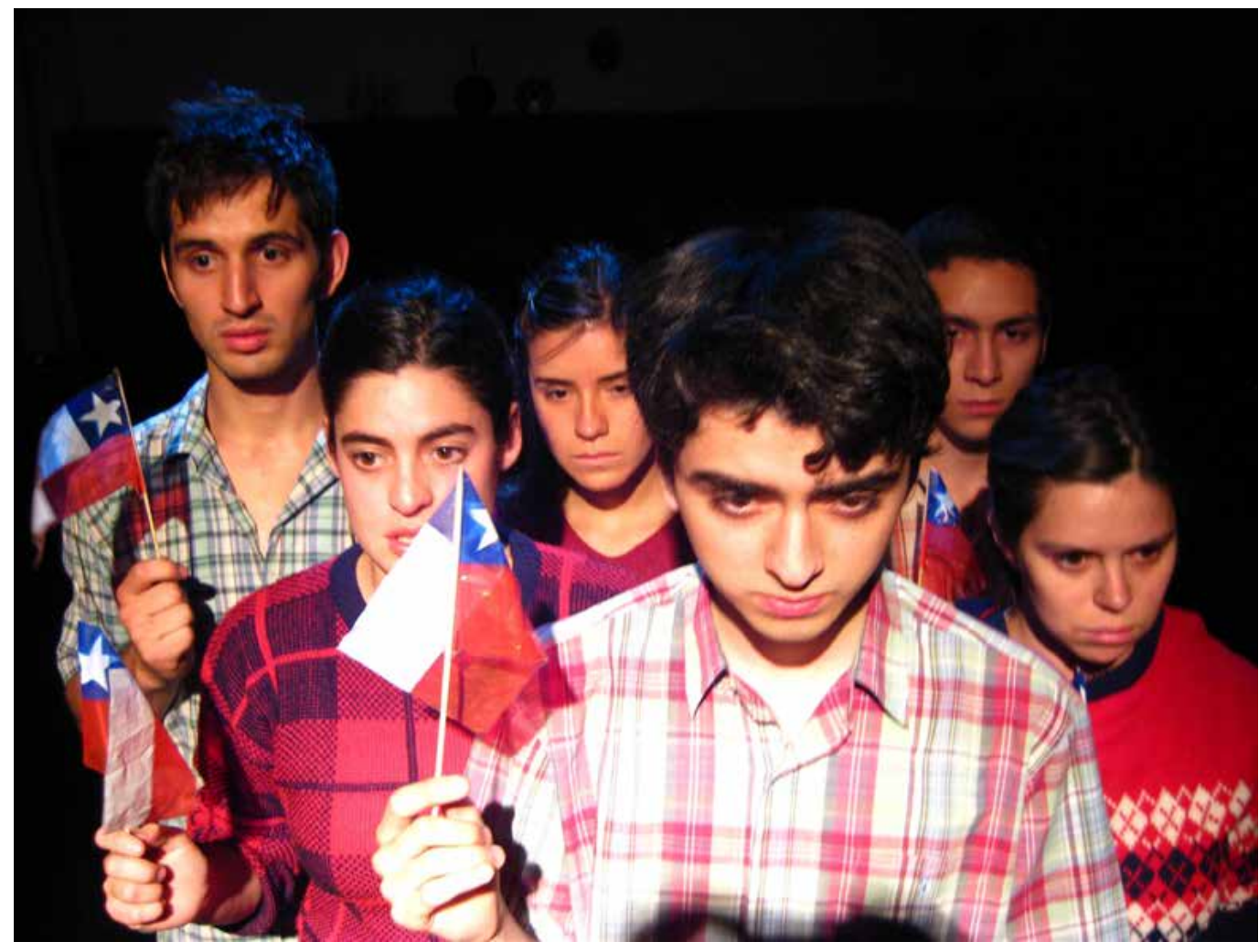

Figura 1. Pablo Dubott, Andrea Soto, Macarena Béjares, Simón Lobos, Carolina Quito, Álvaro Manríquez en escena de la muestra de la investigación Teatro y memoria: estrategias de re-presentación y elaboración escénica de la memoria traumática infantil. Campus Oriente Universidad Católica,
octubre de 2008. (Fotografía de Ornella de la Vega).

A finales de 2011, cuatro años después de la muestra del laboratorio, retomé el proyecto, esta vez con mi compañía Teatro de Patio 5 . Junto con la asistente de dirección Ornella de la Vega revisamos el amplio registro del trabajo del primer laboratorio e identificamos las metodologías que resultaron más eficaces. Planificamos esta segunda etapa a partir del material que rescataríamos del trabajo de 2011 y las nuevas formas de performativización de los testimonios que queríamos probar en esta fase. De este trabajo surgió la obra profesional de teatro testimonial Pajarito nuevo la lleva, que tuvo funciones en julio, agosto y septiembre de 2012 en Santiago de Chile, en espacios teatrales, como el Centro Cultural Gabriela Mistral y Teatro el Puente, y espacios de la memoria, como el Museo de la Memoria y la Casa de Memoria José Domingo Cañas. 
La obra fue seleccionada por la editorial inglesa Bloomsbury para ser incluida en el volumen The Methuen Anthology of Testimonial Plays, publicado en 2014 y editado por Alison Forsyth (Contreras 2014). El libro incluye el guion de la obra en su versión profesional y un ensayo de mi autoría, en el que explico algunas de los procesos escénicos constructivos.

\section{PREMISA METODOLÓGICA: SOBRE LA INVESTIGACIÓN PERFORMATIVA}

El objetivo general de la investigación exigía una metodología, cuyo pivote fuera la práctica escénica. Tal como se planteó, la idea era explorar desde la escena las posibilidades de puesta en cuerpo de los testimonios. La investigación Teatro y memoria: estrategias de representación y elaboración escénica de la memoria traumática infantil requería entonces una aproximación metodológica que correspondiera con lo que Frayling (1997) denomina investigación a través del arte. Este autor distingue tres tipos de investigación en artes. En primer lugar, la investigación sobre las artes que implica preguntas definidas, hipótesis y la utilización de instrumentos que muchas veces se toman prestados de otras disciplinas, como la semiótica, la estética, o los estudios culturales. Este tipo de investigación es lo que Josette Féral (2009) ha denominado "investigación clásica en artes". En este tipo de investigaciones, la práctica artística entra como objeto de estudio. El segundo tipo de investigación definido por Frayling es la investigación para las artes, que aporta instrumentos o insumos para el trabajo artístico. Sería el caso de investigaciones que buscan generar tecnologías para el trabajo artístico. Por último, el tercer tipo, que es al que corresponde la investigación que estoy analizando, es la investigación a través de las artes, que se distingue de las anteriores en que genera conocimiento nuevo y de frontera a partir de la creación artística. En el ámbito de las artes escénicas, Kershaw (2009) ha llamado este modelo performance como investigación (performance as research), modelo que se caracteriza por el papel que ocupan las prácticas performativas en la generación del conocimiento, que pueden ser parte de la metodología o el resultado de la investigación. Brad Haseman (2007), investigador australiano, se refiere a este tipo de investigación como un nuevo paradigma que denomina la investigación performativa: este tipo de investigación genera conocimiento a partir de la práctica escénica y en ese sentido se distingue respecto del paradigma cualitativo y cuantitativo. La investigación performativa se articula en torno a preguntas que solo pueden ser tratadas desde la práctica, preguntas que en definitiva interrogan sobre el quehacer, los procedimientos y las metodologías artísticas. La investigación performativa permite entonces la utilización de medios expresivos no lineales ni literales y admite, por ejemplo, la articulación de preguntas/procedimientos en formas visuales, corpóreas, sonoras, táctiles (Haseman 2007).

Es importante destacar que no cualquier práctica escénica puede ser considerada como investigación. Tal como plantea Henk Borgdorff:

La práctica artística puede ser calificada como investigación cuando su propósito es ampliar nuestro conocimiento y entendimiento a través de una investigación original. Empieza con preguntas que son pertinentes para el contexto de la investigación y el mundo del arte, y emplea métodos que son apropiados para el futuro estudio. El proceso y los resultado de la investigación están apropiadamente documentados y son difundidos entre la comunidad investigadora y el público más amplio. $(2010,33)$ 
En nuestra investigación tomamos al pie de la letra la indicación de Borgdorff y registramos en detalle todas las fases del proceso: las sesiones de trabajo con los actores fueron grabadas y los actores llevaron registro de su proceso en una bitácora. En la fase final del proyecto, invitamos al psicólogo Ivan Smirnow a realizar un trabajo de observación participante, con el fin de registrar el proceso de creación de la obra destacando las modalidades mediante las cuales se tomaban los acuerdos, la emergencia de ideas creativas y la resolución de problemas escénicos por parte del grupo. Todo el material registrado a lo largo del proceso sirvió para articular una completa exégesis que nos permitiera difundir los hallazgos de la investigación en la comunidad académica. Es interesante constatar que en nuestro diseño metodológico se contemplaba desde el inicio dos tipos de resultados. Por un lado, la obra de teatro propiamente tal, entendida como resultado del proceso; y por otro, la generación de documentos académicos que pudieran complementar los descubrimientos escénicos.

Elegimos esta metodología, ya que nos parecía que las preguntas requerían una aproximación de esta naturaleza, pero también porque nos adherimos a la premisa epistemológica de este nuevo paradigma. Nuestro proceso necesitaba responder a una ética y política de la investigación, cuyo norte no fuera la creación de una obra, sino la indagación de un determinado problema.

Como plantea Josette Féral, las investigaciones conducidas desde la práctica artística (en este caso escénica) "instauran una palabra más dinámica —aunque también más parcelariaque consigue conciliar la objetividad de la observación con la subjetividad que comporta cualquier obra centrada en sí misma" $(2009,326)$. Nuestra investigación performativa se adhirió a una epistemología que reconoce la capacidad de las prácticas y los cuerpos para generar conocimiento. Desde esta óptica se plantea que el pensar o el hacer no están separados, sino que deben trabajar sinérgicamente en la búsqueda de nuevos conocimientos. Nos pareció que esta mirada podría contribuir a saldar aquella cisura que a veces se percibe como insalvable entre la investigación académica sobre el teatro y la investigación que hacen los artistas mediante su propia práctica.

El papel que tuvimos los investigadores que trabajamos en el laboratorio teatral corresponde a lo que Donald Schön (1982) ha caracterizado como un practicante reflectivo o, en nuestras palabras, un investigador/creador. Mi papel como investigadora distaba de pretender una distancia entre el objeto y el sujeto de estudio, más bien valoraba nuestra capacidad como artistas participantes en el proceso para reflexionar en y desde la acción. La posición de enunciación que ocupo en la redacción de este documento corresponde justamente a la de una practicante reflexiva. Dirigí los ensayos, estuve liderando el proceso escénico exploratorio y en estos momentos, a años de distancia, elaboro una reflexión de índole académica que puede poner en circulación los hallazgos del trabajo en otras plataformas. Espero que esta exégesis sirva para inspirar el trabajo escénico con testimonios en otros contextos y contribuya a fortalecer el acervo de investigaciones conducidas por la práctica en América Latina.

La complejidad del material abre una multiplicidad de posibles hebras de análisis, desde la experiencia de los actores, la recepción por parte de los espectadores, la toma de decisiones creativas, las implicancias éticas y políticas del trabajo, entre muchas otras. En este artículo, me concentraré en identificar las distintas estrategias de puesta en escena y puesta en cuerpo de los testimonios recolectados y daré cuenta de algunas de las posibles estrategias de re-elaboración escénica de la memoria del posconflicto. 


\section{LA MATERIA PRIMA: LOS TESTIMONIOS}

Como explican Cristina Demaria y Daly McDonald, el juicio de Adolf Eichmann inauguró nuevas formas de testimonialidad que respondían directamente al imperativo moral, ético e histórico de no olvidar el Holocausto. Europa invistió las prácticas testimoniales casi como un amuleto para ahuyentar la posibilidad de repetición de las atrocidades cometidas. En la posguerra, se produjo lo que Annette Wieviorka (1998) denominó "la era del testimonio", era marcada por la necesidad de reconstruir un relato colectivo sobre el pasado. La recurrencia de las prácticas testimoniales, y en particular del género literario del testimonio, fue tan persistente que Wiesel (1998) planteó incluso que el testimonio era el nuevo y más prominente producto artístico de la cultura contemporánea. De a poco el testimonio se fue desplazando desde los márgenes hacia el centro de la cultura constituyendo, incluso hasta el día de hoy, una de las prácticas privilegiadas para la reconstrucción del pasado y uno de los objetos de análisis preferidos de los estudios culturales, semióticos, literarios y artísticos.

Como ya he manifestado en otro documento (Contreras 2013), la trayectoria del testimonio en América Latina se distingue de las condiciones de producción y puesta en circulación del contexto europeo. En América Latina, el testimonio emergió como un contradiscurso, intrínsecamente antijerárquico, antisistémico y antihegemónico. Mientras el testimonio en Europa responde a una visión prevalente (incluso jurídicamente establecida) respecto de lo que sucedió en el Holocausto, entendida como una verdad que no puede ser negada, en América Latina el testimonio crece y se cría desde sus inicios como una práctica de resistencia que debe luchar constantemente por su legitimidad.

Las primeras narrativas testimoniales latinoamericanas surgen en el contexto de la las izquierdas revolucionarias de la década de 1960, que buscan la visibilización de "los sin voz". Luego, fue el contexto de las dictaduras cívico-militares — que más o menos en la misma época se impusieron en los países de la región - el humus que favoreció una significativa proliferación de las prácticas testimoniales. Tal como explica María Olga Ruiz:

Desde la instalación de las dictaduras cívico-militares, los testimonios fueron una herramienta

fundamental para superar la negación institucional de los crímenes del terrorismo de Estado y

su carácter sistemático. Sin embargo, sus alcances superaron la mera denuncia, instalándose

como un reto a las estructuras tradicionales no solo del poder político sino también de la aca-

demia y sus marcos disciplinares. $(2014,124)$

En el horizonte dictatorial, el testimonio sirvió entonces para validar y legitimar los relatos subjetivos y contrahegemónicos que intentaban resistir la represión. El testimonio como género literario y práctica social sobrevivió las dictaduras para instalarse durante las posdictaduras como una de las herramientas privilegiadas para relevar en la arena pública la palabra de las víctimas a las violaciones de los derechos humanos.

Como artistas investigadores, fuimos conscientes desde el primer momento que los testimonios con los que trabajamos se situaban en el contexto del giro testimonial latinoamericano. Los testimonios eran para nosotros puertas de acceso a una historia personal que se desplegaba sobre un trasfondo cultural e histórico, que no solo respondía a la situación particular de las dictaduras, sino que implicaba también las resonancias de los distintos usos y prácticas testimoniales en América Latina. 
Tal vez una de las características diferenciales de nuestro material testimonial era que recuperaba experiencias infantiles. A diferencia de los testimonios de personas adultas, este ejercicio testimonial requería conectarse con aquellas zonas de la memoria más lejanas, donde los recuerdos se hacen difusos. La mayoría de los testimoniantes reconocía no haber hablado de sus experiencias infantiles en la dictadura hace mucho tiempo, por lo que el convivio testimonial exigía una reconstrucción mnémica activa. El hecho de apelar a experiencias infantiles se tradujo en el discursivo en una temporalidad disgregada, plagada de saltos en el tiempo, con actantes inestables que no siempre podían identificarse con nombres y una figurativización atravesada también por la imaginación propia de los niños. Como expresa una de las testimoniantes del proyecto (figura 2):

Sí, es que fue más que nada algo que vi, que viví, pero, o sea, varias cosas que más que nada te hacen volar la imaginación de cómo eras de chica, cosas que no te puedes explicar. Recuerdo que salíamos a tocar las ollas y todas esas cosas, pero después nos íbamos a acostar, pero después todo el ruido que había en la calle era como sentir mucha gente gritando, llantos, vals al aire. Recuerdo siempre que sentía que eran muchas personas que estaban sentadas y gritaban "va a caer", pero mucha gente, no sé, me imaginaba que estaban como sentadas [...], quizás el canto era como ordenadito y que podrían haber estado todos ordenados cantando, pero yo creo que era mucha gente que andaba por las calles cantando "y va a caer", así como el estadio. Esos ruidos siempre me trasladan a esas noches de mucho enfrentamiento, imagínate para un niño en ese lugar y no verlo, entonces te empiezas a imaginar cosas. (entrevista con Gabriela, 2008) ${ }^{6}$

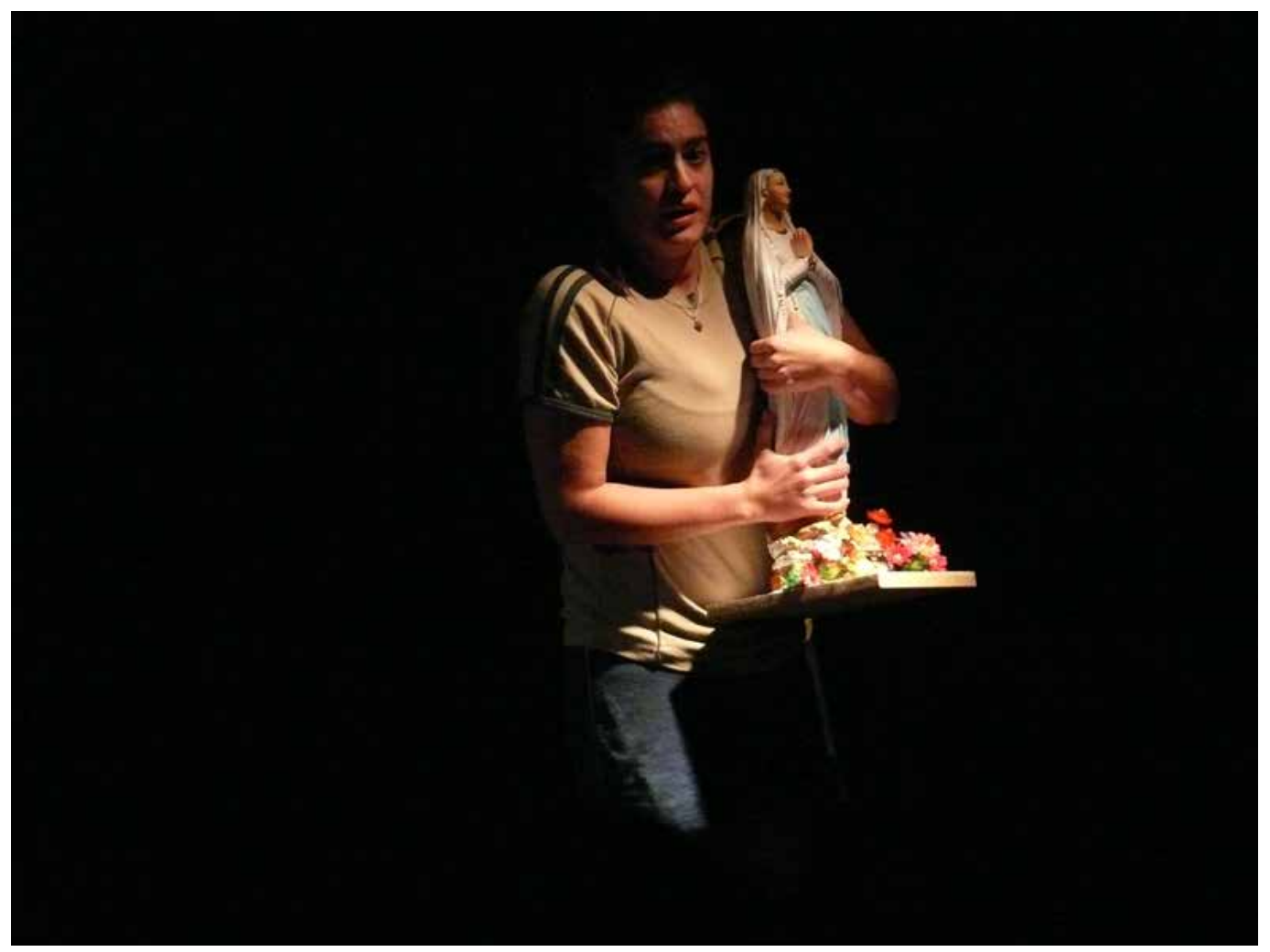

Figura 2. Andrea Soto en escena de la muestra de la investigación Teatro y memoria: estrategias de re-presentación y elaboración escénica de la memoria traumática infantil. Campus Oriente Universidad Católica, octubre de 2008. (Fotografía de Ornella de la Vega). 
Tal vez por el mismo hecho de tratarse de experiencias infantiles, el silencio desempeñó también un papel importante en la configuración discursiva de los testimonios. En general, el testimonio se ha entendido como un dispositivo que se juega en los límites de la decibilidad. Como ha relevado el ya clásico texto de Giorgio Agamben, el testimonio solo logra traducir la presencia de una ausencia, la imposibilidad del habla, allí donde la imposibilidad cobra existencia a través de una posibilidad de hablar $(2002,153)$. La problematización de los límites del lenguaje era aún más evidente en los testimonios de experiencias infantiles, en los cuales el acto verbal no alcanzaba a contener la complejidad de una experiencia que aparecía como demasiado lejana. En ese sentido, la praxis testimonial de nuestros entrevistados se situaba en la dimensión del resto, del exceso, de aquello que el lenguaje no puede expresar en su totalidad existencial.

Como directora del laboratorio teatral, una vez realizada esta primera conceptualización respecto de las filiaciones y modalidades de aparición del material testimonial específico con el que trabajábamos, tuve que empezar otro tipo de trabajo que se localizaba en el territorio de lo escénico. Trabajé, entonces, con la hipótesis metodológica que planteaba que el resto excedente no semantizable, permanecía en los cuerpos de los testimoniantes. Allí donde la articulación discursiva daba paso a silencios y balbuceos era posible constatar cómo aparecían gestos corporales que entraban en diálogo con las fracturas discursivas. Las constantes fluctuaciones de las respuestas demostraban esta dificultad, sobre todo cuando Nicholls hacía preguntas que apuntaban a recuerdos "olvidados." Un análisis detallado de los videos muestra cómo los entrevistados recuperaban in situ una memoria que no sabían tener. Las preguntas los sorprenden, los dejan literalmente sin palabras, pero el cuerpo re-acciona, reactúa y vuelve a vincular el pasado con un presente desde donde se podía pesquisar esa forma de vida anterior. La gestualidad en estos momentos cobraba una radical importancia, parecía a ratos que el cuerpo fuera encontrando la hebra que permitía relatar la experiencia pasada. Un ejemplo muy claro de esto es la entrevista de Marcela, quien, ante la pregunta " ¿Y te acuerdas de juegos más tradicionales?", vacila, titubea y luego inicia a mover sus manos mimando el juego tradicional chileno de la "payaya" (que consiste en lanzar cinco piedras y atraparlas en el aire con la misma mano). Después de unos segundos dice: "A la payaya" (entrevista con Marcela, 2008). El análisis de los videos nos revelaba cómo muchas veces era el gesto el que conducía al recuerdo y en última instancia lo construía.

Fue interesante cómo esta hipótesis que surgió desde el trabajo escénico permeó la recolección de testimonios. Junto con Nicholls y Grass discutimos esta posibilidad y decidimos en las entrevistas sucesivas pedir a los entrevistados que "contestaran" algunas preguntas solo con gestos. Por ejemplo, Nicholls preguntaba hacia el final de la entrevista: "Si tuvieras que hacer un gesto que representara tu experiencia en esa época, ¿cuál sería?". Este trasvasije desde lo escénico a la metodología de la historia oral es un excelente ejemplo de la colaboración interdisciplinaria que se dio durante todo el proyecto. En el trabajo, no primaba lo escénico respecto de lo teórico o lo metodológico: todo se fue tejiendo con un auténtico afán de influencia disciplinaria mutua.

Una vez que trabajamos en la comprensión de los testimonios y la creación de ciertas categorías de análisis, surgió la pregunta más crucial de todo el proceso: ¿cómo traducir y trasponer el relato testimonial a una práctica performativa? Esta pregunta volvía una cuestión con la que se han enfrentado los teatristas desde inicios del siglo XX. 
Los inicios del siglo XX vieron dos formas de poner en escena la relación entre teatro, testimonio y archivo, que serían determinantes para todo el desarrollo de la dramaturgia por venir. Al revisitar la tradición del rapsoda (que se mueve entre la actuación/mímesis y la narración/ diéresis), Brecht problematizó la cuestión del testigo. Aquí, el actor se desdoblaba entre el personaje (que da testimonio de su existencia a través de la acción) y el actor distanciado (que da testimonio de una acción que él observa, al modo de un "testigo ocular"). Paralelamente al desarrollo de este teatro del testimonio, Piscator inauguró lo que luego se conocería como "teatro documental"; en este caso, la relación con la realidad no se da a través del testigo, sino por medio del uso del archivo (Grass 2014, 108).

América Latina recuperó esta problemática, de nuevo, con herramientas y cuestionamientos situados desde su personalidad local. Es posible distinguir dos grandes momentos del teatro testimonial en América Latina. En un primer momento, en las décadas de 1960 y 1970, el teatro se comprometió con la misión política de poner en escena a los "sin voz" (Bravo Elizondo 1982). Las obras, de fuerte impronta política, intentaban poner en valor las historias de quienes circulaban en los márgenes del poder. En esta misma fase, se pueden situar las obras testimoniales que afrontaban temas directamente relacionados con la violación a los derechos humanos en las dictaduras. En un segundo momento, que inicia con el siglo XXI y sigue aún vigente, el teatro testimonial desplazó su interés desde la vocación de denuncia al cuestionamiento de la posibilidad de escenificar un referente extrateatral. El teatro testimonial que se ha desarrollado en las últimas décadas no responde así a una vocación restitutiva, sino que puja hacia la problematización de lo real como posibilidad escénica.

Los procesos constructivos de las obras testimoniales han transitado así desde una pretensión de veracidad historiográfica hacia una concepción que privilegia la verosimilitud y la autenticidad. En este contexto, lo que entra en juego no es "lo real", sino el "efecto de realidad". Las nuevas formas de teatro del real trabajan en el plano de la legitimidad que evoca un real que de todas formas permanece inaccesible (Martin 2013). Es en ese sentido que como postulan Alison Forsyth y Chris Mergson el teatro de lo real ha complicado las nociones de autenticidad: "El mordaz requerimiento que pedía a la forma documental ser necesariamente equivalente a un testigo intachable y objetivo de los eventos públicos, ha sido desafiada para situar la verdad histórica en un lugar de batalla y contestación [traducción mía]" $(2009,6)$.

En línea con las últimas tendencias de prácticas de lo real, nuestro trabajo de puesta en cuerpo de los testimonios se distanció radicalmente de la vocación restitutiva para autoconcebirse como un ejercicio de interpretación, en el que lo importante era la mediación artística de los testimonios. La dialéctica entre lo real y la mediación surgió como el nudo central que debíamos desenredar. El propio trabajo escénico fue aportando distintas formas de interrogación a lo real, cuestionamientos que nos llevaban a generar prácticas donde más que una representación de lo real se trabaja en pos de lo que Duarte (2013) denomina construcción de lo real mediante la teatralidad. Nuestra indagación se propuso así eludir y quebrar toda posibilidad de aserción directa a lo real y se instaló como un ejercicio de reflexión corporizada sobre los pliegues del lenguaje hablado y también sobre la teatralidad como posibilidad de mediación: ¿qué podíamos decir nosotros como artistas respecto de los testimonios? ¿Cuál es nuestro papel como mediadores? ¿Cómo transparentar en escénica y evidenciar el trabajo de mediación escénica? 


\section{LA MEMORIA DEL CUERPO: SISTEMAS INTERCORPÓREOS PARA DESCIFRAR UNA MEMORIA}

En el espíritu de eludir toda posibilidad de aserción directa a lo real, durante la primera fase del trabajo con actores nos propusimos evitar un trabajo actoral que tendiera a la cohesión psicológica, corporal y biográfica de los testimoniantes. Por eso junto con De la Vega decidimos dosificar el acceso a la información testimonial para evitar que los actores trabajaran generando personajes. A veces les facilitábamos solo fragmentos de las entrevistas transcritas, otras veces fragmentos de los audios originales e incluso alguna vez mostramos un video pero sin audio para concentrar la atención en los aspectos corporales de los entrevistados. Esta decisión impidió que los actores y las actrices tuvieran acceso al panorama general de los testimonios y que se aproximaran al material como si fuera un texto dramático, es decir, trabajando para generar personas dramatae. Esperábamos sortear así la trampa de caer en una construcción mimética de los testimoniantes que respondería a la peligrosa tentación referencial.

Fuimos incluso más radicales: evitamos poner en escena cualquier ilustración gestual y mimética de las anécdotas relatadas para privilegiar otros modos de construcción y reconstrucción del material de la memoria. En este trabajo empezó a cobrar siempre mayor relevancia el cuerpo y nos dimos cuenta de que desde los testimonios emanaba la predominancia de la corporalidad no solo en las figuras del discurso, sino también como operador de la enunciación. Los recuerdos estaban profundamente anclados en los cuerpos, las sensaciones, los gestos.

Decidí, entonces, que la puerta de entrada para el trabajo actoral debían ser también los cuerpos. El cuerpo no sabe imaginar ni puede ser algo distinto de sí, el cuerpo es siempre sí mismo. Utilizando una lógica performativa, en vez de empezar por la representación del material de la memoria que era "fuente", decidí comenzar por los cuerpos que debían interpretar el material. Les pedí a los actores y las actrices que trabajáramos con sus propias memorias corporales, aquellas memorias que se alojan en el cuerpo y que se reactivan en la acción?. Más allá de la memoria emotiva o narrativa de los actores, el trabajo escénico se centró en recuperar mediante la acción aquella memoria que habita el cuerpo y que a veces resulta tan difícil de desentrañar (figura 3).

Les pedí a los actores que hicieran dos partituras físicas basadas en un recuerdo infantil. Las partituras físicas debían mostrar las acciones físicas ligadas a los recuerdos. Una vez que los actores tenían partituras físicas a partir de sus propias memorias infantiles, sobrepusimos estas acciones corporales con los relatos testimoniales: de esa forma los actores y las actrices reaccionan a la vez y en modo simultáneo al relato testimonial y a sus propias memorias corporales. Este tipo de trabajo tiene sus antecedentes en la técnica de las acciones físicas (Grotowoski 1990, Richards 2005 y Barba 2009), que sugiere una acumulación de capas de significación que no siempre son coherentes. Así, mientras el actor ejecuta una partitura física que se refiere a un determinado contenido, dice un texto que no corresponde a la acción física. Siguiendo los principios expuestos por la actriz del Odin Teatret Roberta Carreri (2013), pensaba que esta acumulación de capas de significación permitiría densificar la acción y generar distintas posibilidades interpretativas en el espectador. La memoria corporal de los actores se activó así para funcionar como bisagra entre los relatos de la memoria de los testimoniantes y el público. El actor en esta situación de re-presentación se libera de imaginar ficcionalmente la experiencia de un otro y le permite concentrarse en su propia experiencia corpórea. 


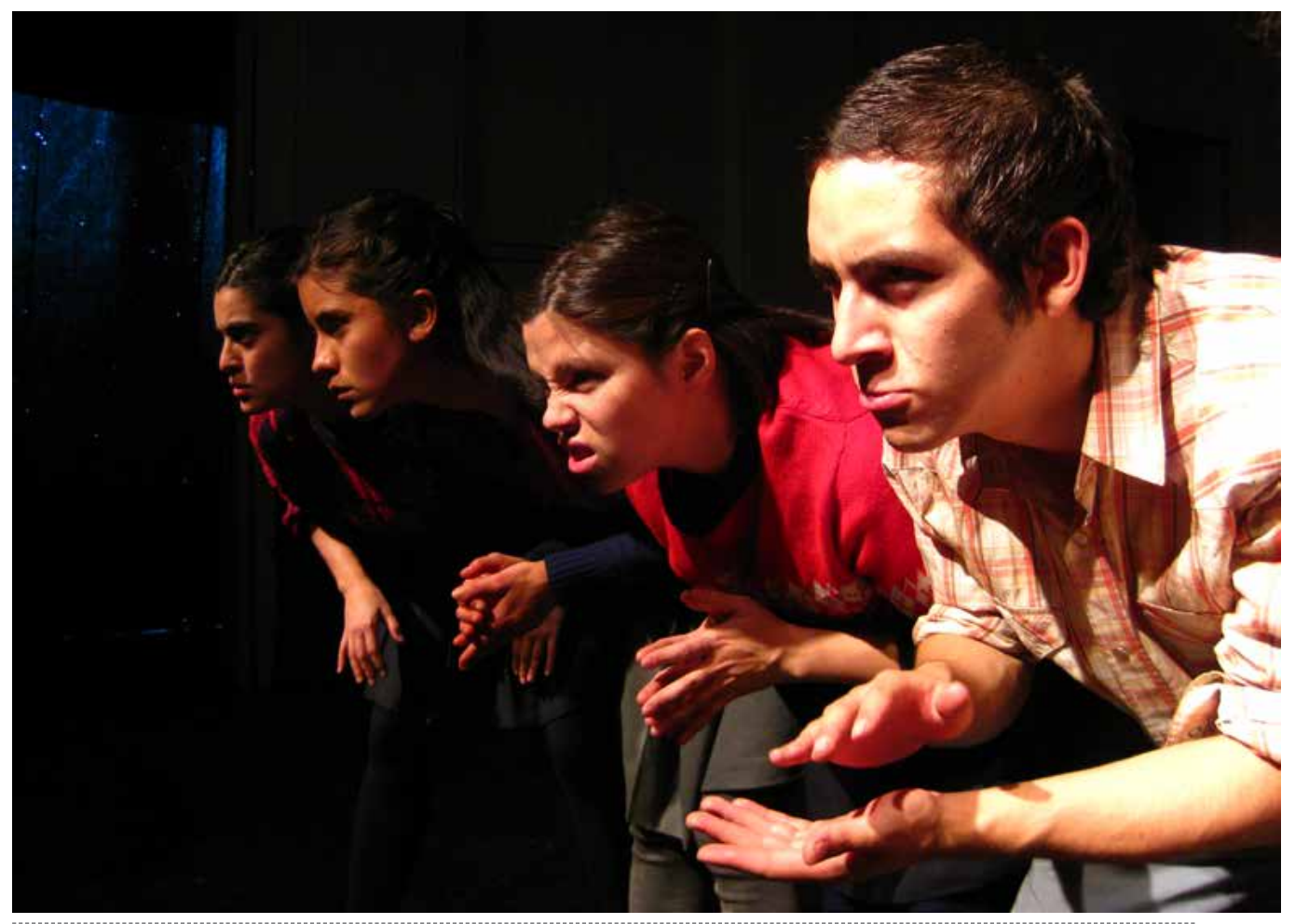

Figura 3. Álvaro Manríquez, Andrea Soto, Macarena Béjares, Carolina Quito en escena de la muestra de la investigación Teatro y memoria: estrategias de re-presentación y elaboración escénica de la memoria traumática infantil. Campus Oriente Universidad Católica, octubre de 2008. (Fotografía de Teatro de Patio)

Tal como he planteado antes, la articulación no coherente ni lógica de la acción física, las imágenes psicofísicas del actor y el texto propicia que la experiencia del espectador no se limite a la comprensión del texto verbal, sino que también pueda conectarse en lo intercorporal (Contreras 2008). El proceso me fue revelando que la especificidad de nuestro trabajo escénico con la memoria residía en una comunicación discursiva, pero también en una comunicación intercorpórea algo que se comunica desde la memoria del cuerpo a la memoria del cuerpo. Nuestro proceso permitía que el convivio entre el actor o la actriz y el espectador permitiera una re-elaboración del discurso de la memoria, pero también de esos "restos" que exceden la dimensión del lenguaje verbal. En el trabajo se fue constatando cómo el cuerpo del actor actuaba como dispositivo de comunicación entre aquellos restos no verbalizables del testimonio y la experiencia espectatorial. La experiencia del laboratorio demostró que el trabajo de re-actuación simultánea de las memorias relatadas por otros y vividas por el actor resulta eficaz, es decir, logra comunicar y transformar la percepción sobre el pasado del espectador. Lo interesante es que esta eficacia no se basa en la narración verbal, sino que se sustenta principalmente en los cuerpos de los participantes (tanto de los actores como de los espectadores). La densificación de la acción (gracias al trabajo sinérgico entre memorias de los entrevistados y memorias de los actores) facilita una comunicación intercorporal que abre dimensiones comunicacionales que pueden prescindir de las palabras. Cuando esto ocurre, la acción probablemente resuena en la memoria del espectador, porque "cuaja" con el sentido anclado en la memoria colectiva.

Fui también percatándome de la efectividad política de estas operaciones de escenificación de testimonios: la puesta en cuerpo de los testimonios permitía compartir y comunicar aquellas zonas de la experiencia que, por ser remanentes del discurso, quedan excluidas de las páginas de la historia. Estos procesos constructivos de escenificación de los testimonios abrían la posibilidad de comunicación de relatos no hegemónicos y de experiencias profundamente 
personales que encuentran escasas vías de comunicación oficial. Los testimonios comunicados no aparecían entonces como textos autónomos, sino que, al contrario, se instalaban como intertextos plagados de mediaciones y traducciones.

Al cabo de cuatro meses de trabajo laboratorial, hicimos una muestra abierta al público a la que concurrieron los testimoniantes y otros invitados. Fue muy interesante comprobar cómo esta técnica de superposición de memorias podía en efecto comunicar memorias corporizadas. Uno de los testimoniantes comentó: "Volví a sentirme como un niño, mi cuerpo volvió a esas sensaciones y me acordé de cosas que no me había acordado antes, ni siquiera en la entrevista" (Ignacio, comunicación personal).

El trabajo de escenificación de los testimonios implica darle una nueva vida al pasado para transmitirlo en el acontecer de un presente que se comparte en el aquí y ahora de la performance. Se trata, en este sentido, de una estrategia que privilegia lo que Diana Taylor (2003) denomina repertorio, es decir, aquel tipo de memoria que no pertenece al ámbito del archivo o el documento, sino que se transmite a partir de la acción encarnada de los sujetos. Taylor explica que las performances son instancias privilegiadas para conservar la memoria de repertorios, una memoria que habita el cuerpo de los participantes y se cristaliza en gestos, voces y movimientos, que se transmiten en la copresencia propia de la performatividad. Desde este punto de vista, la muestra de 2008 transformó los documentos en repertorio. Esta estrategia de escenificación sirvió para dar cuenta de las vivencias personales, pero también para construir un pasado compartido. Mediante la performance el pasado se hizo visible y adquirió nuevas valencias y sentidos. La transmisión del testimonio implicó también la expansión de los testigos: quienes vieron la muestra se convirtieron en testigos de ese pasado a la vez tan personal y colectivo. Experiencias como estas sirven al doble propósito de contar la historia y de re-actuarla activando el repertorio que al re-presentarse se construye y transforma.

A la luz del trabajo realizado en el primer laboratorio puedo distinguir al menos cuatro momentos de traducción de la experiencia de los entrevistados:

1. La huella corporal. Como plantea Fontanille (2004), el cuerpo conserva las huellas de los contactos sensoriales con otros cuerpos, por lo que puede funcionar como un archivo no semántico de la experiencia. El primer momento es entonces el momento apenas posterior a la inscripción de la experiencia en el cuerpo del sujeto. Hablamos de traducción y de mediación puesto que no sería posible concebir una huella no mediada. La huella no es el calco de una experiencia, es desde el momento de su inscripción un artificio que tiene un grado, aunque incipiente, de semioticidad.

2. De la experiencia vivida a la experiencia susceptible de ser compartida. A este momento podríamos llamarlo de protoverbalización. Es el momento en el que las huellas contenidas en el cuerpo inician a organizarse y adquieren una valencia diferencial que tiende a la semantización. Este es el nivel que se interfiere en el caso del trauma psíquico. Tal como explica la teoría freudiana, el trauma sería un exceso de energía que no puede ligarse, es decir que no encuentra un lugar en la configuración semántica y por tanto resta incomunicable.

3. De la experiencia individual a la experiencia intersubjetiva. Este nivel es tal vez el más evidente o del que más se ha teorizado. Se trata del momento en el cual la experiencia pasa de la dimensión privada a la dimensión intersubjetiva, en general diádica, por ejemplo en el caso de nuestra investigación en la instancia de las entrevistas. Este traspaso no es exclusivamente verbal, sino que se da multimodalmente a través de comunicación preverbal, visual, gestual, corporal, etc. 
4. La puesta en cuerpo de la experiencia de otro. Este es lo que hicimos en el laboratorio en el sentido de pasar de la dimensión diádica intersubjetiva a la puesta en cuerpo de la experiencia relatada por otro, lo cual implica evidentemente una apertura hacia la dimensión pública. El arte sería un mediador en este tercer nivel, que permitiría elaboraciones, relecturas y difusión de la experiencia individual.

\section{EL MONTAJE PROFESIONAL DE “PAJARITO NUEVO LA LLEVA”}

En 2011, junto con Teatro de Patio, la compañía profesional que dirijo, decidimos retomar el trabajo realizado en 2008, con el objeto de crear una obra que pudiera mostrarse a un público más amplio. La idea era partir de los ejercicios del laboratorio de 2008 para luego reelaborar el material escénico, revisar los testimonios y finalmente crear una obra de teatro testimonial. Fiel con el espíritu de experimentación, decidimos que la salida a la arena profesional no debía desviar el foco experimental y por tanto resolvimos explorar nuevas formas de puesta en escena y evitar compromisos con salas de teatro convencionales y apuntar más bien a espacios alternativos, como antiguos centros de detención y tortura.

La obra se tituló Pajarito nuevo la lleva, dicho chileno infantil que expresa que el último niño o niña por ingresar en un juego se lleva la peor parte. Por ejemplo, si un grupo de niños está jugando al pillarse y llega un nuevo integrante al juego, este deberá cumplir el papel de quien pilla. Nuestros testimonios hablaban justamente de cómo los niños, recién llegados a la vida social, les tocó en efecto la peor parte, debían soportar la angustia, la represión y miedo sin tener herramientas suficientes para poder hacer frente a lo que vivían. Los adultos, quienes deberían haber sido los responsables de proteger la integridad física y mental de los niños, no fueron capaces de explicar, verbalizar y, en última instancia, contener a los niños.

Esta segunda etapa implicó un cambio en la metodología de trabajo en lo que refiere al acceso del material de memoria por parte de los actores. Como esta vez trabajaba con actores profesionales que en su gran mayoría ya habían trabajado conmigo antes, decidí que esta vez podríamos dar a conocer todo el material testimonial a los intérpretes. La primera parte del trabajo consistió en una exhaustiva revisión de las transcripciones, los videos y los audios. De esta forma, a diferencia de 2008 , los intérpretes conocían con claridad la historia personal de los testimoniantes.

Un segundo cambio en el énfasis metodológico fue que, si bien conservamos la idea de que no fuera una obra documental, esta vez flexibilizamos la posibilidad de trabajar con anécdotas claras de los testimonios. Si en 2008 tuvimos la precaución de evitar cualquier ilustración mediante la desarticulación del nivel de la acción con la memoria física de los actores, esta vez nos arriesgamos a generar material físico ilustrativo, pero con la precaución de no presentarlo en sincronía con el relato verbal testimonial que daba cuenta de esa determinada anécdota. Así, los cuerpos podían, por ejemplo, estar actuando una escena de la vida infantil de uno de los testimoniantes, pero jamás dirían al mismo tiempo el relato de ese momento (figura 5).

En esta etapa, una de las premisas que guiaron el trabajo fue la noción de Umberto Eco (2008) de interpretación intersistémica, es decir, cuando se interpretan signos de un cierto sistema semiótico mediante signos de otro sistema semiótico. Tanto las transcripciones (textos verbales escritos) como los registros audiovisuales (imágenes y sonidos en secuencia) tuvieron que transmutarse en una práctica performativa, es decir, en acciones de los actores 


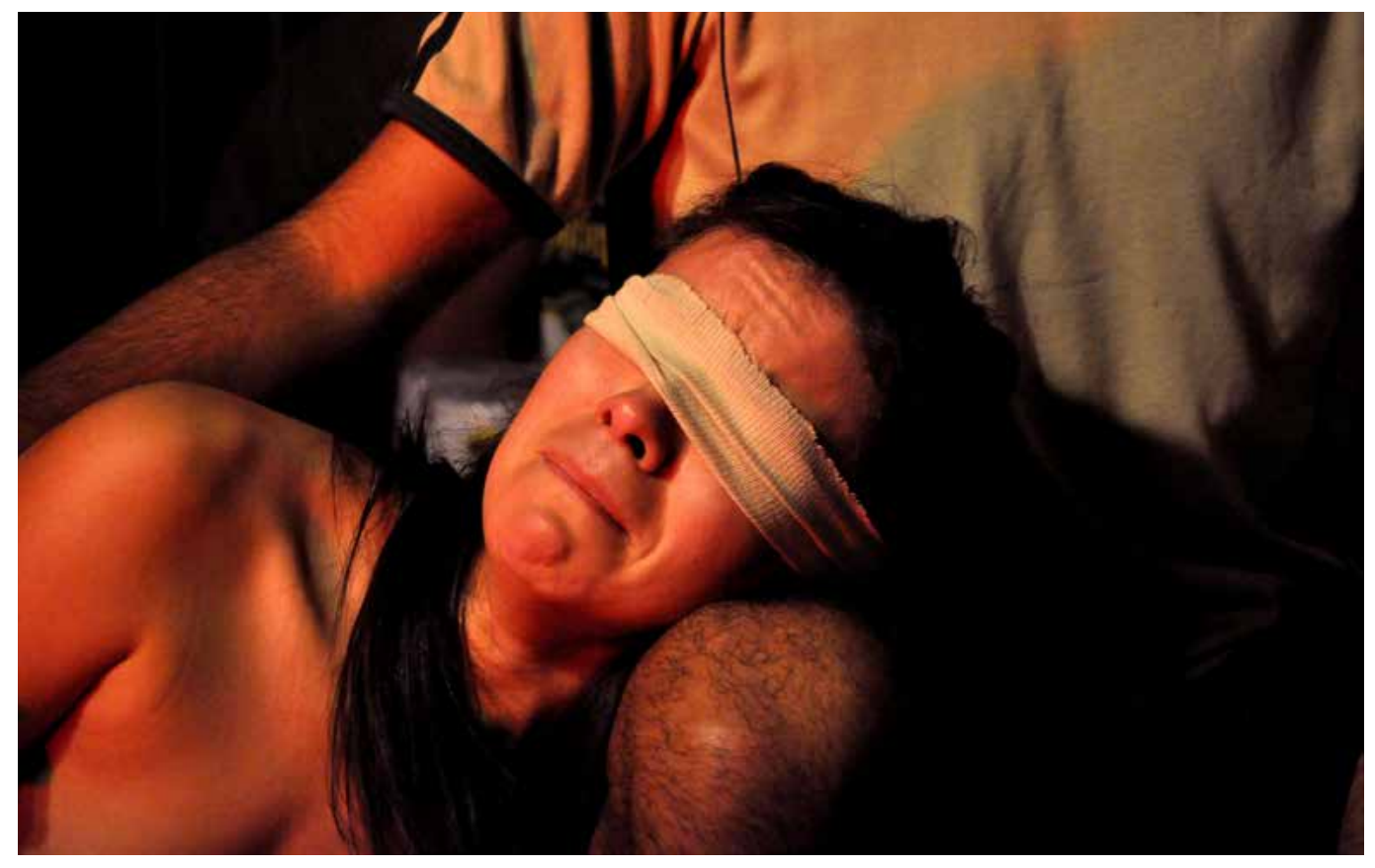

Figura 5. Carolina Quito en escena de Pajarito nuevo la lleva. Centro Cultural Gabriela Mistral, Santiago de Chile, julio de 2012 (Fotografía de Teatro de Patio).

en escena realizados "ante" los espectadores. Para adquirir la valencia de teatralidad, los testimonios se hicieron cuerpo, acción y presencia. Esta transmutación, que claramente no es ni automática ni inmediata, implica una cierta licencia interpretativa que requiere los dos tipos de operaciones, que Eco (2008) definió como hacer ver lo no dicho y no hacer ver lo dicho.

La conversión del testimonio a la práctica performativa exige hacer ver lo no dicho: hay detalles que el relato verbal puede omitir, pero que la puesta en escena no puede no mostrar. Por ejemplo, cuando una de las testimoniantes, Sara, cuenta cómo su padre fue agredido por militares en la plaza de su barrio, dice:

Habíamos ido a comprar pan y mi papá andaba con muletas y yo como si nada, caminando con él, trayendo la bolsa del pan y de repente ya —en la plaza se juntaba todo lo que era military empezaron a correr, y me acuerdo muy bien que le botan el bastón a mi papi y él se cae, y garabatos. (entrevista, 2008)

En este relato sobre la agresión que sufrió su padre, Sara no especifica cuántos militares estaban en la plaza, ¿eran tres, cuatro, quince? La transmutación performática exige mostrar aquello que no se ha dicho, es por tanto inevitable realizar una apuesta interpretativa que muestre en escena y por ende especifique el número de militares que participaron de este acto vejatorio. La escena, que es un retrato del episodio de violencia, cambia su sentido y significado si se decide poner dos militares que agreden al padre de Jenny o cuarenta. Se trata de una apuesta interpretativa que inevitablemente afecta la comprensión del pasado relatado.

Como directora, era consciente que inevitablemente tenía que interpretar el episodio relatado y construir la escena a partir de una mirada. La creación se tornó una empresa con una fuerte valencia ética. Sabía que no podía documentar la realidad, pero tampoco quería falsear un recuerdo. Decidí crear una escena donde los personajes circularan por los cuerpos de los actores, un mismo actor podía a momentos ser la víctima, el testigo o el agresor. De esta forma, por un lado, sorteaba la necesidad de "inventar" un número de militares 
y a la vez transparentaba mi accionar como directora. Esta estrategia me permitió dejar ver la apuesta interpretativa y delatar la maquinaria teatral para contar dos cosas a la vez: contamos escénicamente el episodio del testimonio y contamos también cómo nuestro dispositivo actoral y teatral se enfrentó a este material para hacerlo cuerpo y carne.

La otra operación complementaria es la selección del complejo y rico universo de las entrevistas que implica no hacer ver lo dicho o más bien no hacer ver (todo) lo dicho. Los testimonios contenían muchísima información tanto en el contenido (los detalles de los relatos, la narrativización del pasado) como en la expresión (el modo cómo se contaban los recuerdos, qué gestos acompañaban el relato verbal, las inflexiones y la entonación de la voz, los recorridos de las miradas, etc.). Una puesta en escena que abarcara todo este universo es francamente impensable, por lo que la interpretación intersistémica demandó, por ende, una decisión sobre qué aspectos de los testimonios serían reportados en la práctica performativa. En modo complementario, si en la primera operación tuvimos que "crear" algo que no estaba dicho, en esta segunda operación la tarea fue "cortar" o "editar" el material de la memoria.

Si observo a posteriori, me parece que se pueden distinguir dos estrategias de selección o dos niveles en los cuales esa selección ocurrió: el nivel de contenido y el nivel de la expresión. Utilizando la nomenclatura semiótica, podríamos pensar que los testimonios tienen un contenido (articulaciones semánticas que configuran un significado) que es vehiculado por una determinada expresión (una materialidad que funciona como significante). Contenido y expresión son en realidad indisolubles, puesto que se co-construyen mutuamente: ese contenido testimonial solo puede "existir" en relación con el significado específico que lo particulariza.

En el entendido teórico que no existe una prevalencia de uno sobre otro, es decir en que no es posible pensar que el contenido sobreviva en la mente de los entrevistados sino cuando se hace materia en una ocurrencia expresiva particular, es que quise trabajar en ambos niveles. Por la complejidad de la operación y sobre todo por la ausencia de referentes de trabajo con esta metodología, decidí plantear ambos niveles pero por separado.

\section{EL NIVEL DEL CONTENIDO: LAS ISOTOPÍAS}

Una primera selección fue en el contenido de los testimonios, es decir, revisando el aspecto semántico de los testimonios. Este trabajo lo realicé con ayuda de la asistente de dirección con quien nos estudiamos todas las transcripciones en busca de aquello que se "repetía" o que "surgía transversalmente" en las entrevistas. Fuimos identificando lo que en semiótica se denomina isotopía ${ }^{8}$ o sea, recurrencias semánticas en los textos. Tomamos como universo textual el total de las transcripciones y fuimos viendo qué recurrencias se verificaban en modo transversal. Fue así como llegamos a detectar las siguientes isotopías:

- los juegos infantiles,

- $\quad$ el miedo,

- el sonido de los helicópteros,

- no saber qué sucede, no tener explicaciones de los padres. 
Una vez que identificamos las isotopías, decidí reportar en la muestra en escena, también transversalmente, estos temas. Para evitar una aproximación abstracta o discursiva a estas isotopías, me propuse un fuerte anclaje en la corporalidad: las isotopías debían ser jugadas en y por el cuerpo. Así fue como la columna vertebral de la puesta en escena se construyó a partir de juegos infantiles, algunos directamente tomados de los testimonios y otros de la experiencia de los actores. Los juegos hechos carne nunca se mostraban univalentemente. Por ejemplo el juego de la gallinita ciega", que consiste en cubrir los ojos de un niño o niña con un pañuelo y luego hacerlo girar sobre su eje con el propósito de desorientarlo para luego pedirle que "pille" al resto de los niños que gritan el nombre del vendado mientras aprovechando su situación de indefensión le pegan por la espalda, se puso en escena en forma ambivalente. Este juego resonaba con cómo los testimonios relataban que los prisioneros políticos eran tratados en los campos por los militares. En escena el juego deja de ser un juego de niños para mostrar también el horror de la crueldad de los victimarios de la dictadura.

El miedo se representó con gestos repartidos a lo largo de toda la muestra que como leitmotivs gestuales recurrían en distintos momentos. La mayoría de las veces estos gestos estaban asociados a algo que ocurría fuera del espacio escénico, como si indicaran las amenazas en el espacio exterior. El terror a los helicópteros, terror que permanece incluso hasta hoy en alguno de los entrevistados, fue también una imagen que trabajamos con los actores, quienes cada cierto tiempo, a veces al unísono, otras veces en modo individual, alzaban su cabeza para "acusar" la presencia de un helicóptero que sobrevolaba el espacio simbólico. A veces el gesto de los actores denotaba miedo y otras veces felicidad, tal como nos relataba Ignacio, quien confesaba que de niño se alegraba de ver helicópteros y aviones porque le parecía estar en una película.

Las isotopías daban cuenta de aquello que había quedado cristalizado en la memoria colectiva. Como experiencias comunes, se posicionaron como un nódulo central de lo que el conflicto político significó en la vida de los niños de la época o tal vez - y me inclino más a esta posibilidad - son las representaciones más hegemónicas, aquellas que han resistido en el tiempo y que han adquirido mayor valencia en la memoria colectiva. En cualquier caso, se trata de sensaciones que retratan la experiencia infantil de la época y que por tanto tienen una mayor posibilidad de enganche con las memorias individuales de los espectadores. Algunos de los espectadores a Pajarito nuevo la lleva manifestaron que habíamos retratado verosímilmente "el ánimo" de la época. Creo que la verosimilitud de la atmósfera puede explicarse gracias al trabajo performativo con las isotopías. Estoy segura de que una adecuada selección de las isotopías y su acertada "performativización" permite la resonancia afectiva, corporal y cognitiva en los espectadores y genera un enganche, sobre todo, con la generación que vivenció esa época. Era curioso notar cómo para las generaciones más jóvenes muchos de estos gestos carecían de importancia e incluso no eran percibidos. Por ejemplo, un joven espectador después me preguntó por qué los actores miraban hacia arriba. Este gesto, totalmente comprensible para los adultos que vivieron en dictadura y que era inmediatamente interpretado como la reacción a los helicópteros, resultaba un gesto insignificante para aquellos que no habían tenido la experiencia, y que tampoco recibían una explicación verbal de la puesta en escena. 


\section{LAS FORMAS DE LA EXPRESIÓN: VOCES MÚLTIPLES}

Como mencioné, la transmutación de los testimonios a una práctica performativa se realizó en dos niveles paralelos: el de contenido y el de la expresión. En el ámbito de la expresión, me pareció particularmente relevante dar cuenta de cómo se narran las memorias y mediante qué estrategias se construye el propio pasado. Esta fue una de las premisas de trabajo también en la primera muestra del laboratorio teatral.

Al igual que en el contenido, el universo expresivo de la muestra de testimonios era infinito. Era factible dar cuenta de estas formas de narración de la memoria individual a partir de muchos indicios, los testimonios presentaban diversos filamentos, cada uno de las cuales abría líneas de investigación disímiles. Me pareció que uno de los aspectos más cruciales en la expresión de las memorias infantiles que debían estar presentes en la práctica performativa era la vocalidad de los testimonios; por un lado, la sonoridad del relato hablado, y por otro, la multiplicidad de voces que la muestra recoge.

Tan importante como el contenido de los testimonios eran las voces de los testimoniantes, que mediante titubeos, susurros, llantos y risas lograban relatar su pasado. La lectura de las transcripciones es una experiencia completamente distinta de la escucha de las voces reales de los testimoniantes, que producía un efecto de verosimilitud difícilmente reproducible por un actor en escena. Me pareció urgente entonces compartir con los espectadores la conmovedora experiencia de escuchar los testimonios en su forma original, de sentir la voz real de quien narraba su pasado.

En primera instancia, pensamos en "traer" la voz de los entrevistados como sonido en off, pero desechamos esta opción, puesto que nos pareció que desvirtuaba una de las características de los testimonios: su intimidad. Los testimonios nacen en la seguridad de una conversación diádica que la amplificación del sonido pervertía y creaba una distancia entre el espectador y la voz narrante (figura 6).

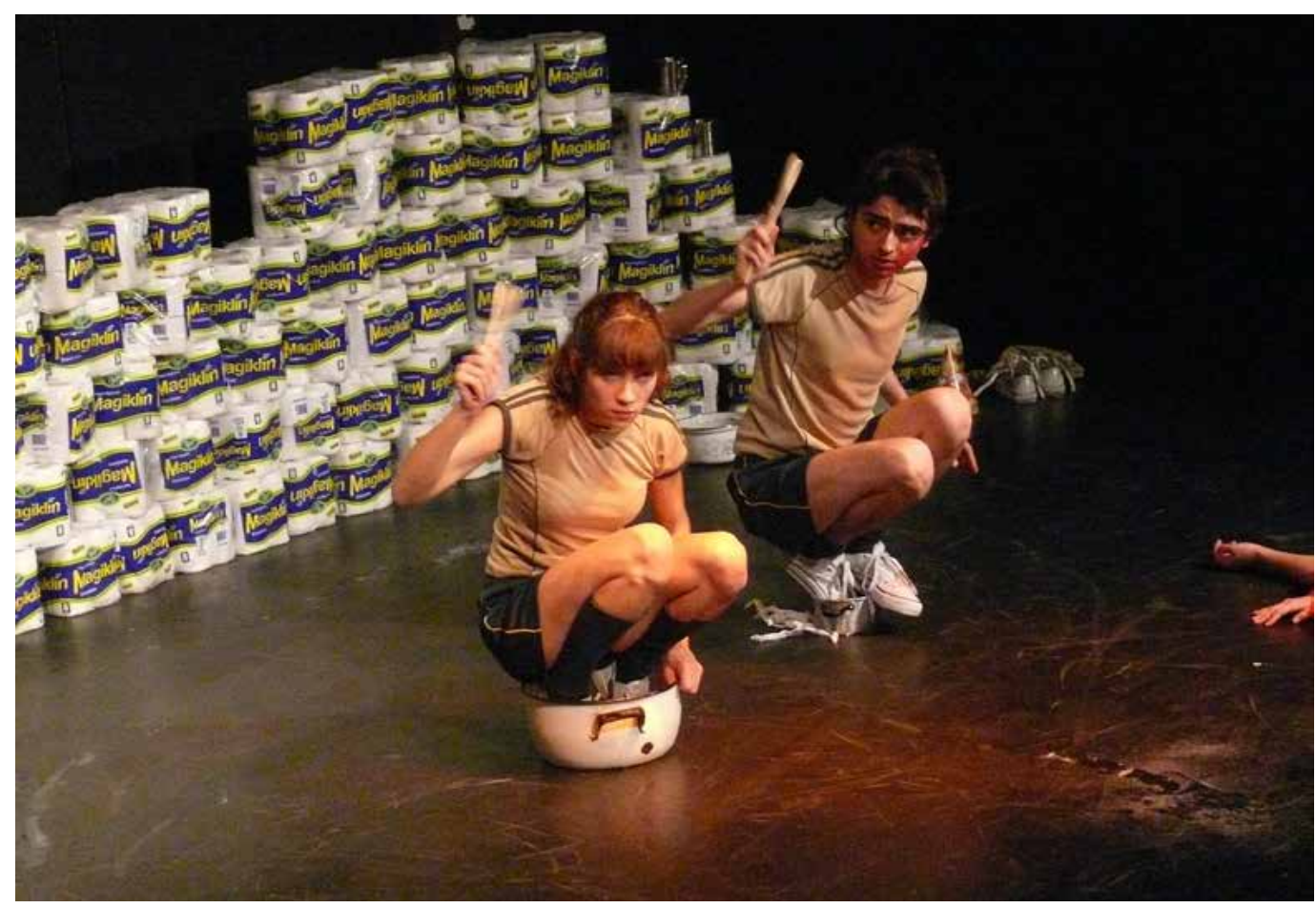

Figura 6. Andrea Pelegri, Pablo Dubott en escena de Pajarito nuevo la lleva. Centro Cultural Gabriela Mistral, Santiago de Chile, julio de 2012.(Fotografía de Teatro de Patio). 
Así fue que, ya en 2008, se nos ocurrió que cada espectador tuviera un dispositivo de audio personal (en 2008 un discman, en 2012 un reproductor de MP3) que le permitiera escuchar fragmentos de distintos testimonios en la intimidad que otorgan los audífonos. Los espectadores eran instruidos al inicio de la muestra a activar sus aparatos cuando vieran en escena la palabra PLAY que aparecía casi a los diez minutos de empezada la muestra. El registro de audio estaba matemáticamente sincronizado con la acción de los actores y las actrices. De hecho, los actores tenían a la vista un cronómetro que definía la duración exacta de cada una de las escenas, lo cual nos permitió que en algunas escenas el registro de audio estuviera en silencio para posibilitar que los actores hablaran en escena. Después de muchos ensayos, el calce era perfecto.

En 2008, el registro de audio que los espectadores escuchaban contenía una edición de fragmentos de los testimonios, dos canciones y los momentos de silencio que coincidían con las escenas "habladas" desde el escenario. Este formato nos permitió diversificar las fuentes de las voces que provenían alternadamente desde el escenario y desde las grabaciones. Por turnos el espectador escuchaba las voces de los actores y las voces originales de los testimoniantes. Esta estrategia permitió delatar el dispositivo teatral y dar cuenta a cada momento de dos niveles del trabajo: los testimonios originales y la operación de interpretación (intersistémica) que resultó en la práctica performativa. En 2012 cobró más relevancia la idea de "intervención".Tal como la memoria está constantemente intervenida por el presente, la información que uno maneja u olvida, los megarrelatos históricos, decidimos que las bandas sonoras no podían limitarse a documentar los testimonios originales, sino que nos pareció importante en este nivel también transparentar nuestra mediación como artistas. Es asó como, en 2012, además de los fragmentos de los testimonios originales, incluimos las voces de los actores que leían los testimonios originales o en algunos casos relataban sus propias memorias ${ }^{9}$.

Las bandas sonoras de los aparatos de reproducción individual contenían en 2012 los siguientes tipos de audios:

- fragmentos de los testimonios originales,

- $\quad$ canciones de la época,

- grabación de los actores leyendo la transcripción de los testimonios,

- actores contando sus propias memorias,

- sonoridades: el sonido de la calle, de los helicópteros, de niños jugando, la cortina de Radio Moscú y Radio Cooperativa.

Respecto de las opciones tomadas en el primer laboratorio, en 2012 la experiencia auditiva (y cognitiva y afectiva) de los espectadores se complejizó. Creo que esta nueva forma de aproximación al sonido que emanaba de los audífonos nos permitió desacralizar los testimonios originales y entrar en el pantanoso terreno de la recuperación de la memoria. Tal como decíamos, el teatro testimonial no pretende el despojo de la teatralidad para instalar una verdad, sino que problematiza los límites de lo real. Pajarito nuevo la lleva no intentaba dar a conocer los testimonios, sino hacer testimonio (escénico) del testimonio. En la obra, el testimonio devenía testimonio gracias a la transparencia del dispositivo teatral, similarmente a lo que plantea Ileana Dieguez sobre las artes contemporáneas que trabajan con memoria: 
Devenir documento —más que trabajar desde una vocación estrictamente documental— y devenir testimonio son dos condiciones muy recurrentes en el arte contemporáneo. Quizás la pregunta no está en el sentido de indagar "¿de qué son prueba estas imágenes?", más que representar, el problema está en lo que evocan las imágenes de hoy. Esa memoria, esa visión, ese saber que a veces callamos por angustia o por miedo. $(2011,87)$

El segundo aspecto que se trabajó en la expresión dice relación con la multiplicidad y heterogeneidad de los testimonios. Si las isotopías tendían a un movimiento homogeneizante que buscaba recurrencias en las entrevistas, en la expresión me pareció fundamental rescatar la heterogeneidad de los testimonios, que más allá de los aspectos coincidentes involucraban necesariamente una individualidad del sujeto que reconstruía su pasado.

Esto fue transmutado en la puesta en escena mediante la incorporación de distintas pistas de audio. En la muestra de 2008, los espectadores podían elegir entre dos "bandas sonoras" distintas que determinaban lo que escuchaban mientras presenciaban la muestra. En 2012, radicalizamos esta diversificación incluyendo otras dos versiones de audio. Me pareció un modo adecuado para multiplicar la experiencia individual de los espectadores en la práctica performativa. Los espectadores, debían elegir (sin saber qué elegían) entre cuatro grupos de MP3 desplegados en una mesa frente a la puerta de entrada a la sala. Cada montón estaba identificado por una letra A, B, C, D. Sin mayor información, el espectador tomaba una opción y elegía qué banda sonora escucharía.

Este formato iba en contra de una de las convenciones teatrales más importantes, a saber, la construcción de un público homogéneo que ve y escucha lo mismo al mismo tiempo que los actores y las actrices lo emiten en escena. Este formato con audífonos, en vez de construir un público homogéneo, construye una acumulación de individuos que acceden a distintas versiones auditivas de la acción en escena. Este dispositivo era también una metáfora de cómo funciona y se construye la memoria y la historia. Cada espectador, tal como los niños de la dictadura, interpretaba lo que vivenciaba según la información a la que accedía. De esta forma los espectadores ocupaban un lugar análogo a los niños de la dictadura: su experiencia estaba coloreada por las voces que alcanzaban a escuchar y que definían su posibilidad de entendimiento de lo que pasaba en sus familias y en el país.

Pajarito nuevo la lleva permitía que cada espectador interpretara lo que veía según lo que le había tocado escuchar (lo que había elegido sin saber las consecuencias de su elección), así como cada sujeto social interpreta el pasado y la historia a partir de los referentes a los que accede.

\section{CONCLUSIONES}

La investigación performativa Teatro y memoria: estrategias de re-presentación y elaboración escénica de la memoria traumática infantil tenía por objeto explorar y sistematizar distintas modalidades de puesta en cuerpo y escenificación de testimonios de personas que fueron niños y niñas durante la dictadura en Chile. La aproximación metodológica correspondió a una investigación conducida por la práctica escénica, donde las indagaciones y los hallazgos se configuraron como prácticas corporizadas. En conjunto con el trabajo práctico, se llevó a cabo un trabajo de análisis y reflexión teórico que ha dado paso a una serie de artículos científicos en los que se reflexiona en torno a los procesos constructivos de la obra (figura 7). 


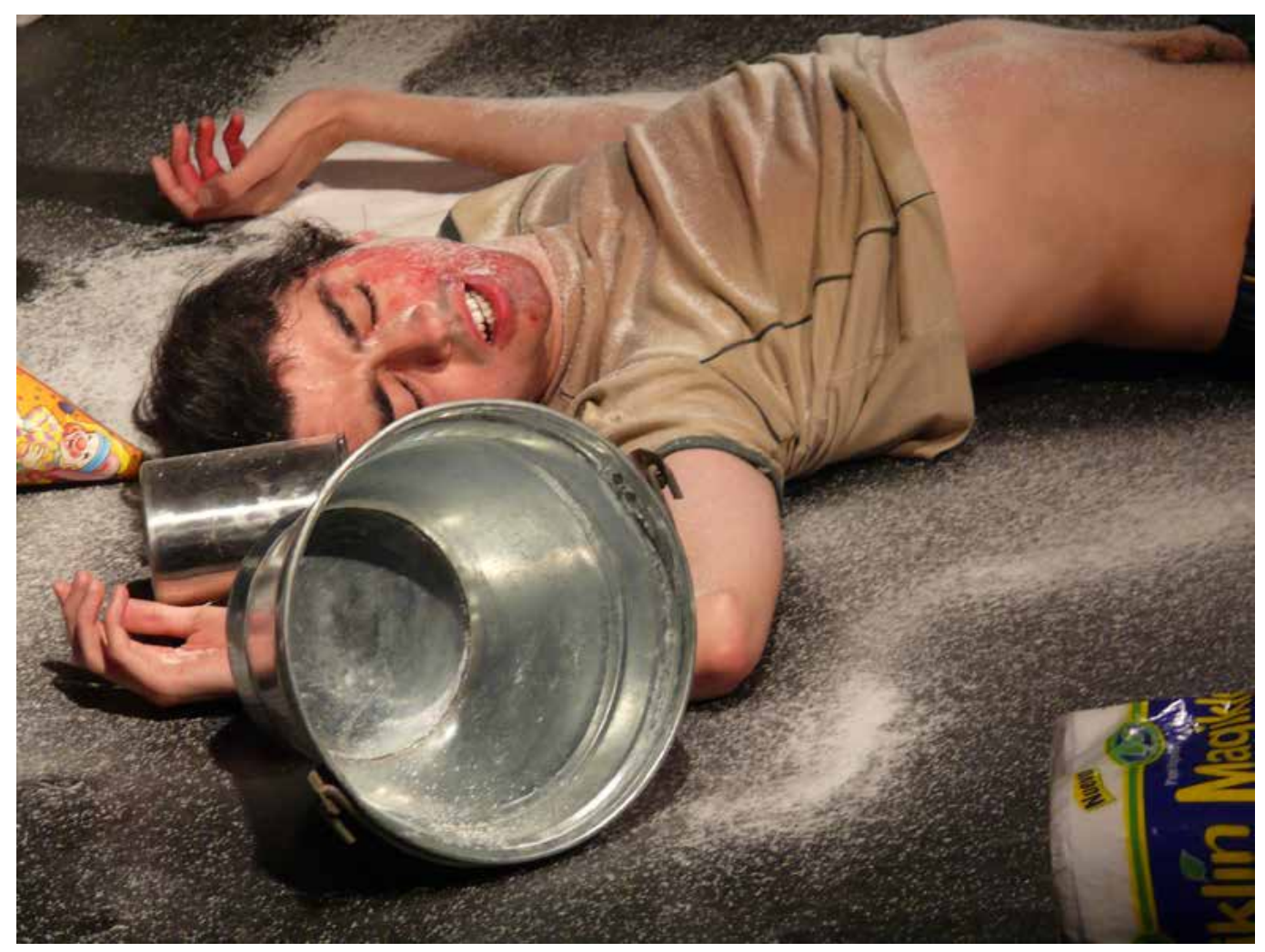

Figura 7. Pablo Dubott en escena de Pajarito nuevo la lleva. Centro Cultural Gabriela Mistral, Santiago de Chile, julio de 2012 (Fotografía de Teatro de Patio).

El ejercicio de revisión de la genética de los procesos constructivos que he realizado en esta sede transparenta no solo las estrategias de escenificación, sino también la postura ética y política desde la que nos enfrentamos al trabajo. Si tuviera que sintetizar en un concepto el trabajo realizado, este sería el principio de mediación, mediación que se produjo en distintos sentidos y dimensiones. Por un lado, la mediación dentro del equipo de investigación que estaba conformado por personas con distintas formaciones disciplinarias. Desde las primeras reuniones, cuando formulamos el proyecto, se planteó la necesidad de negociar qué herramientas y métodos utilizaríamos para obtener qué tipo de resultados. La interdisciplinariedad apareció, como pocas veces, no como un deseo, sino como una verdadera necesidad. La forma cómo se realizaron las entrevistas se fue permeando de los hallazgos del laboratorio de investigación escénica mientras que el trabajo con los actores también se iba retroalimentando con la expertisse de Grass y Nicholls, quienes conceptualizaban el trabajo a la luz de sus propias competencias disciplinarias.

Otro tipo de mediación en el equipo se produjo entre las investigadoras y los actores y las actrices. En general, los actores habían nacido en la democracia, mientras que las investigadoras, aunque de distintas edades, habían vivido en primera persona la dictadura. Aprendimos mutuamente de aquello que conocíamos e ignorábamos respecto de los lugares de habla de cada una de las generaciones involucradas en el proyecto. Las aclaraciones, los comentarios y las explicaciones abundaban para explicar a los actores algunos de los hechos relatados por los testimoniantes.

Otra gran frontera de mediación es la que se producía entre los actores y las actrices y los espectadores. Como mencioné, los cuerpos de los actores funcionaban como bisagra entre los testimonios y el espectador que interpretaba los relatos gracias a la acción escénica 
y los audios. Operábamos con el propósito explícito de transparentar la mediación, evidenciar el dispositivo teatral, poner en juego también nuestras propias apuestas interpretativas. De este modo, por un lado, movilizábamos la memoria testimonial, y por otro, dejábamos traslucir la teatralidad del ejercicio de mediación. Fue esto tal vez lo que nos permitió esquivar la pretensión documental para habitar el pliegue, que se hacía más o menos cómodo, de la interpretación artística.

La prevalencia del principio de mediación instauró una política del trabajo que se empecinaba en trabajar creativamente en el complejo y paradojal estatus epistemológico del testimonio. Nunca simplificamos, siempre tendimos hacia la complejidad. Esto fue tal vez el mayor compromiso político del equipo de investigación y de creación, que a la larga refleja también una política de la memoria, donde la memoria no se traspasa, comunica o activa, sino que se co-construye, interpreta y moviliza.

\section{NOTAS}

1 Los estudios sobre el complejo proceso de construcción y recuperación de la memoria histórica de la dictadura en Chile son muchos. Sobre la amnesia impuesta en la denominada transición a la democracia, véase en particular Stern (2000), Lechner y Guell (2006) y Nicholls (2007).

2 Para una revisión sobre la tradición de los Laboratorios Teatrales de la Escuela de Teatro de la Universidad Católica, véase Grass (2011).

3 Para una reseña más completa sobre la metodología utilizada para la recolección de testimonios, véase Contreras, Grass y Nichols (2009).

4 En el laboratorio teatral participaron las actrices Carolina Quito, Macarena Béjares, Andrea Soto y los actores Álvaro Manríquez, Simón Lobos y Pablo Dubott. La asistente de dirección fue Ornella de la Vega.

5 El elenco de la compañía para esta producción fue este: Andrea Pelegri, Pablo Dubott, Andrea Soto, Vicente Almuna, Luis Aros, Carolina Quito. Asistente de dirección: Ornella de la Vega.

6 Los testimoniantes del proyecto dieron su consentimiento informado para participar de la investigación y accedieron a que sus testimonios fueran utilizados literalmente en la puesta en escena y citados en artículos académicos. Algunos solicitaron que no se revelaran sus nombres verdaderos, por lo que en este documento utilizaré seudónimos. Todas las transcripciones de las entrevistas se encuentran en Laboratorio Teatral Universidad Católica (datos inéditos).

7 El vínculo entre cuerpo y memoria es muy estrecho. El cuerpo es el primer repositorio de la experiencia que va dejando huellas inscritas en su superficie (Fontaille 2004).

8 Una isotopía es una redundancia de semas que da coherencia a una determinada configuración textual.

9 El guión definitivo fue publicado en 2014 en The Methuen Drama Anthology of Testimonial Plays, editado en Londres por Bloomsbury. 


\section{REFERENCIAS}

Agamben, Giorgio. 2002. Lo que queda de Aushwitz: el archivo y el testigo. Valencia: Pre-Textos.

Barba, Eugenio. 2009. On Directing and Dramaturgy: Burning the House. Nueva York: Routledge.

Borgdorff, Henk. 2010. “El debate sobre la investigación en las artes". Cairon: Revista Deficiencias de la Danza 13: 25-46.

Bravo Elizondo, Pedro. 1982. El teatro documental latinoamericano. México: Universidad Nacional Autónoma de México.

Carreri, Roberta. 2013. Huellas en la nieve. Santiago de Chile: Triskel.

Contreras, María José. 2008. “Práctica performativa e intercorporeidad: sobre el contagio de los cuerpos en acción". Revista Apuntes 130: 148-162.

— 2013. "Embodied Testimonial Practices. Teatro Testimonial in Postdictatorship Chile". Versus Quaderni di Semiotica, 107-128.

- 2014. "Pajarito nuevo la lleva: the sounds of the coup". En The Methuen Drama Anthology of Testimonial Plays, editado por Alison Forsyth, 297-330. Londres: Bloomsbury.

Contreras, María José, Milena Grass y Nancy Nicholls. 2009. “Pajarito nuevo la lleva. Teatro e memória: estratégias de representação e elaboração cênica da memória traumática infantil". Revista de Estudos de Literatura Artes e Culturas de Expressão Hispânica 17: 154-172.

Demaria, Cristina y Donald McDonald. 2009. "Introduction." En The Genres of Postconflict Testimonies, editado por Cristina Demaria y Macdonald Daly, 7-23. Nottingham: Critical Culture and Communication Press.

Dieguez, Ileana. 2011. "La práctica artística en contextos de dramas sociales". Latin American Theatre Review 45 (1): 75-93.

Duarte, Coca. 2013. “Estrategias de aproximación a lo real del montaje documental chileno Galvarino". Revista Apuntes de Teatro 138: 40-51.

Eco, Umberto. 2008. Decir casi lo mismo: la traducción como experiencia. Barcelona: Lumen.

Féral, Josette. 2009. "Investigación y creación". Estudis Escènics: Quaderns del'Institut del Teatre 35: 321-326.

Fontanille, Jacques. 2004. Figure del corpo: per una semiótica dell'impronta. Roma: Meltemi.

Forsyth, Alison y Chris Mergson. 2009. Get Real: Documentary Theatre Past and Present. Basingstoke y Nueva York: Palgrave Macmillan.

Frayling, Christopher. 1997. Practice-based Doctorates in the Creative and Performing Arts and Design. Lichfield: UK Council for Graduate Education.

Grass, Milena. 2011. "La investigación de los procesos de creación en la escuela de Teatro UC". Revista Cátedra de Artes 9: 87-105.

- 2014. "Performance de la memoria/teatralidad del testimonio: la puesta en escena del archivo FASIC". Revista A Contracorriente, 12 (1): 107-124.

Grotowski, Jerzy. 1990. “El performer". Revista Apuntes de Teatro 100: 133-135.

Haseman, Brad. 2007. "Rupture and Recognition: Identifying the Performative Research Paradigm". En Practice as Research, Approaches to a Creative Arts Enquiry, editado por Estelle Barret y Barbara Bolt, 147-57. Londres y Nueva York: Tauris.

Kershaw, Baz. 2009. "Introduction." Practice-as-Research in Performance and Screen, editado por Ludivine Allegue, Simon Jones, Baz Kershaw y Angela Piccini, 1-16. Basingstoke: Palgrave.

Lechner, Norbert y Pedro Guell. 2006. “Construcción social de las memorias en la transición chilena". En Subjetividad y Figuras de la Memoria 12: 17-46.

Martin, Carol. 2013. Theatre of the Real. Nueva York: Palgrave Macmillan. 
Nicholls, Nancy. 2007. “Las paradojas de la memoria del pasado reciente en Chile: entre el boom y la negación". Puentes, 22 (7): 34-39.

Richards, Thomas. 2005. Trabajar con Grotowski sobre las acciones físicas. Barcelona: Alba.

Ruiz, Maria Olga. 2014. "Los silencios y las palabras: el testimonio como posibilidad". Revista Atenea 509: 123-137.

Schon, Donald. 1982. The Reflective Practitioner: How Professionals Think in Action. Nueva York: Basic Books.

Stern, Steve. 2000. “De la memoria suelta a la memoria emblemática: hacia el recordar y olvidar como proceso histórico (Chile, 1973-1998)". En Memoria para un nuevo siglo, Chile, miradas a la segunda mitad del siglo XX, editado por Myriam Olguín, 11-33. Santiago: Lom.

Taylor, Diana. 2003. The Archive and Repertoire: Performing Cultural Memory in the Americas. Durham: Duke University Press.

Wiesel, Elie. 1998. "The Holocaust as Literary Inspiration". En Dimensions of the Holocaust, editado por Elliot Lefkovitz, 4-19. Illinois: Northwestern University Press.

Wieviorka, Anette. 1998. L'ère du témoin. París: Plon.

\section{Cómo citar este artículo:}

Contreras Lorenzini, María José. 2017. “Del relato testimonial al cuerpo de la memoria: investigación performativa sobre la escenificación de testimonios de niños chilenos en dictadura" Cuadernos de Música, Artes Visuales y Artes Escénicas 12 (1): 173-196. doi:10.11144/Javeriana.mavae12-1.rtcm. 